\title{
Cloud Cover over the South Pole from Visual Observations, Satellite Retrievals, and Surface-Based Infrared Radiation Measurements
}

\author{
Michael S. TOWN \\ Department of Atmospheric Sciences, University of Washington, Seattle, Washington \\ VON P. WALDEN \\ Department of Geography, University of Idaho, Moscow, Idaho \\ STEPHEN G. WARREN \\ Department of Atmospheric Sciences, University of Washington, Seattle, Washington
}

(Manuscript received 7 February 2006, in final form 30 May 2006)

\begin{abstract}
Estimates of cloud cover over the South Pole are presented from five different data sources: routine visual observations $\left(1957-2004 ; C_{\text {vis }}\right.$ ), surface-based spectral infrared (IR) data $\left(2001 ; C_{\text {PAERI }}\right.$ ), surface-based broadband IR data (1994-2003; $C_{\mathrm{pyr}}$ ), the Extended Advanced Very High Resolution Radiometer (AVHRR) Polar Pathfinder (APP-x) dataset $\left(1994-99 ; C_{\text {APP-x }}\right.$ ), and the International Satellite Cloud Climatology Project (ISCCP) dataset (1994-2003; $C_{\text {ISCCP }}$ ). The seasonal cycle of cloud cover is found to range from $45 \%-50 \%$ during the short summer to a relatively constant $55 \%-65 \%$ during the winter. Relationships between $C_{\mathrm{pyr}}$ and 2-m temperature, 10-m wind speed and direction, and longwave radiation are investigated. It is shown that clouds warm the surface in all seasons, $0.5-1 \mathrm{~K}$ during summer and $3-4 \mathrm{~K}$ during winter. The annual longwave cloud radiative forcing is $18 \mathrm{~W} \mathrm{~m}^{-2}$ for downwelling radiation and 10 $\mathrm{W} \mathrm{m}{ }^{-2}$ for net radiation. The cloud cover datasets are intercompared during the time periods in which they overlap. The nighttime bias of $C_{\text {vis }}$ is worse than previously suspected, by approximately $-20 \%$; $C_{\text {ISCCP }}$ shows some skill during the polar day, while $C_{\mathrm{APP}-\mathrm{x}}$ shows some skill at night. The polar cloud masks for the satellite data reviewed here are not yet accurate enough to reliably derive surface or cloud properties over the East Antarctic Plateau. The best surface-based source of cloud cover in terms of the combination of accuracy and length of record is determined to be $C_{\mathrm{pyr}}$. The use of the $C_{\mathrm{pyr}}$ dataset for further tests of satellite retrievals and for tests of polar models is recommended.
\end{abstract}

\section{Introduction}

In spite of nearly $50 \mathrm{yr}$ of routine weather observations at South Pole Station, cloud cover over the South Pole is still not well known. Estimates of cloud cover from visual observations are poor during the polar night because of the high frequency of optically thin clouds (through which stars can be seen) and inadequate moonlight (Hahn et al. 1995). It is also difficult to determine cloud cover from satellite data over the Poles because of the small contrast in both albedo and

Corresponding author address: Michael S. Town, Department of Atmospheric Sciences, University of Washington, Box 351640, Seattle, WA 98195-1640.

E-mail: mstown@atmos.washington.edu temperature between the snow surface and clouds (Rossow and Schiffer 1999). Cloud cover over the South Pole is of particular interest because South Pole Station is one of only a few sites in the interior of Antarctica that maintain continuous year-round records of meteorological and climatological variables. This record extends back to the International Geophysical Year (IGY) in 1957. Because the East Antarctic Plateau is uniform and flat around the South Pole (surface slope $=2.25 \times 10^{-3}$; Liu et al. 2001), the data collected at South Pole Station can represent a broad region of the plateau.

Data collected at the South Pole are not only of climatological interest to the Antarctic community, but are also useful in evaluating the output of weather and climate forecast models as well as satellite retrievals of 
TABLE 1. The South Pole cloud cover datasets. The ISCCP and APP-x datasets used for the analysis here are limited by availability of the pyrgeometer data used for comparison, as well as their own lengths of record.

\begin{tabular}{cllr}
\hline \hline Cloud cover & Source & \multicolumn{1}{c}{ Method } & Length of record \\
\hline$C_{\text {vis }}$ & SPMO & Visual & $1957-2004$ \\
$C_{\text {PAERI }}$ & SPARCLE & Spectral infrared $(3.3-22 \mu \mathrm{m})$ & 2001 \\
$C_{\text {ISCCP }}$ & ISCCP & 0.65 and $11 \mu \mathrm{m}$ & $1994-2003$ \\
$C_{\text {APP-x }}$ & APP-x & $0.65,0.86,3.75,11$, and $12 \mu \mathrm{m}$ & $1994-1999$ \\
$C_{\mathrm{pyr}}$ & ESRL-GMD & Broadband infrared $(4-50 \mu \mathrm{m})$ & $1994-2003$ \\
\hline
\end{tabular}

climate variables (e.g., Briegleb and Bromwich 1998; Hines et al. 1999; Pavolonis and Key 2003; Guo et al. 2003; Pavolonis et al. 2004; Hines et al. 2004). In addition, understanding the behavior of clouds and their properties is important for understanding Antarctic climate. Lubin et al. (1998) found that changing the specified phase and particle size for Antarctic clouds in the National Center for Atmospheric Research (NCAR) Community Climate Model Version 2 (CCM2) caused significant changes in the atmospheric circulation of the Southern Hemisphere. Other studies have revealed that current cloud parameterizations limit the success of Antarctic climate and weather simulations (Hines et al. 1999, 2004). The problems associated with these parameterizations are due in part to the lack of adequate ground-truth data. Therefore, accurate information about clouds and cloud radiative forcing could provide a more solid foundation on which to test the models.

Prior work on the subject of cloud cover over the South Pole by Town et al. (2005) confirmed a low wintertime bias in visual observations of cloud cover found by Hahn et al. (1995). The results of Town et al. (2005) imply that the low wintertime bias may be much greater than that shown in Hahn et al. (1995), but the results of Town et al. (2005) were based on only $1 \mathrm{yr}$ of data (2001). Retrievals of cloud cover over the South Pole from satellite data have also been reported (Fig. 13 of Hahn et al. 1995; Fig. 2 of Pavolonis and Key 2003). Intercomparison of these results shows that there are still significant discrepancies in climatological cloud cover over the South Pole.

In this work we present five different cloud cover datasets for the South Pole (section 2). The estimates of cloud cover come from routine visual observations of cloud cover, retrievals from a surface-based spectral infrared interferometer, retrievals from climatological satellite datasets, and retrievals from a surface-based broadband pyrgeometer. We intercompare the monthly means and seasonal cycles of the different cloud cover datasets, and examine their trends (section 3). We also examine the relationships between cloud cover and longwave radiative fluxes, $10-\mathrm{m}$ wind speed and direction, and 2-m temperature (section 4). The results are summarized in section 5 .

\section{Cloud cover datasets}

This section presents the following relevant details of the different cloud cover datasets (Table 1): visual observations of cloud cover from 1957 to 2004 taken by the South Pole Meteorological Office (SPMO), $C_{\text {vis }}$; cloud cover derived from spectral infrared radiances during 2001 as part of the South Pole Atmospheric Radiation and Cloud Lidar Experiment (SPARCLE), $C_{\text {PAERI }}$; cloud cover derived from the International Satellite Cloud Climatology Project (ISCCP), $C_{\text {ISCCP; }}$; cloud cover derived from the Extended Advanced Very High Resolution Radiometer (AVHRR) Polar Pathfinder dataset (APP-x), $C_{\mathrm{APP}-\mathrm{x}}$; and cloud cover derived from routine surface-based pyrgeometer measurements made by the Earth System Research Laboratory (ESRL)-Global Monitoring Division (GMD) of the National Oceanic and Atmospheric Administration (NOAA), $C_{\mathrm{pyr}}$.

\section{a. Cloud cover from visual observations}

Monthly mean $C_{\text {vis }}$ presented here is computed from visual observations archived by the Antarctic Data Center at the Space Science and Engineering Center (SSEC) at the University of Wisconsin. The monthly means are computed from two different data formatsan archive of the individual synoptic observations (SO archive), which are recorded 4 times daily, and an archive of daily averages (DA archive). The DA archive was calculated by SPMO from hourly observations from late November to early February and from 6-hourly synoptic observations during the rest of the year. The daily mean sky cover was averaged and rounded to tenths until June 1997; thereafter, octas were reported. The DA archive runs from 1957 through the present. The SO archive runs from 1992 through the present. Our analysis only extends through 2004. All time series or composite averages that relate to the entire 1957-2004 period are from the DA archive. All time series or composite averages that relate to the time period of 1994-2003 are computed directly from the SO archive. The $C_{\text {vis }}$ from the SO archive has the advantage over $C_{\mathrm{vis}}$ from the DA archive in that each month can be treated the same in terms of accuracy because of 
temporal resolution and sampling. Monthly mean $C_{\mathrm{vis}}$ are obtained from the SO archive in all cases for which the synoptic data are available, except when they introduce nonuniformities that may affect trends or seasonal cycles computed here.

Monthly means computed from the DA archive differ from those computed from the SO archive, with an rms difference of about $5 \%$. No doubt some of the discrepancy between the two is a result of the daily averages being calculated from hourly observations from late November to early February. Some of the remaining discrepancies throughout the year may be explained by the loss of accuracy resulting from additional averaging and rounding steps that are applied in producing the DA archive. Some of the discrepancies between the monthly means computed from the SO archive and the DA archive are still unexplained, but they have minimal effects on the long-term averages.

Uncertainty in the monthly means of $C_{\mathrm{vis}}$ resulting from random error is estimated as in Fig. 5 of Warren et al. (1986). In that work, the random errors in a monthly mean resulting from inadequate sampling for grid boxes in northern Europe were estimated through subsampling a larger dataset. For 120-124 observations per month (i.e., 6-hourly data), the uncertainty in the monthly mean is $4 \%$ points. Step functions in the $C_{\text {vis }}$ time series may also be present due to changes in observing practices from one organization to another. The SPMO was operated by several different organizations from 1957 to 2004 (the U.S. Navy, National Weather Service, and independent contractors). The uncertainty introduced by changes in observing practices is not quantified here.

Figure 1 is a histogram of visual observations made during daylight. It shows that $C_{\text {vis }}$ is within 1 octa of clear or overcast $71 \%$ of the time. The World Meteorological Observation (WMO) guidelines for visual observers (WMO 1996) state that if there is the slightest amount of cloud in the sky, then observers are required to classify the sky as 1 octa of cloud cover. Similarly, if there is the slightest bit of clear sky visible between the clouds, then the observers are required to classify the sky as 7 octas of cloud cover. Therefore, calls of either 1 or 7 octas often correspond to essentially clear or overcast skies, respectively. Figure 1 then shows that the sky is essentially clear or overcast $71 \%$ of the time during daylight.

Strengths of the visual observation dataset are its length and regular sampling frequency. During daylight clouds are easily detected because they are being contrasted with a darker background. Weaknesses of the visual dataset include the nighttime observations and inconsistent calibration of observers from year to year.

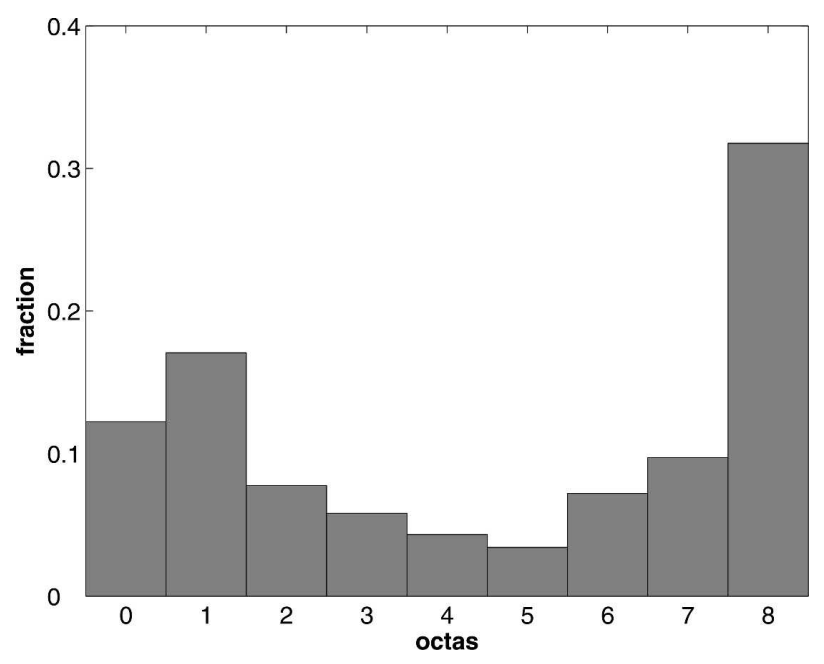

FIG. 1. A histogram of daytime visual observations of cloud cover from 1994 through 2003 (7280 observations total). Cloud cover exhibits a U-shaped distribution, with the result that cloud cover is within 1 octa of being clear or overcast $71 \%$ of the time at South Pole.

\section{b. Cloud cover from surface-based spectral infrared measurements}

Cloud cover was derived from downwelling spectral infrared (IR) data $\left(C_{\mathrm{PAERI}}\right)$ taken as part of SPARCLE (Walden et al. 2001). The spectral IR radiances were observed by the Polar Atmospheric Emitted Radiance Interferometer (PAERI) from January to October 2001. The PAERI has a narrow field of view (FOV; $46 \mathrm{mrad}$ ) and a spectral range of 3.3-22 $\mu \mathrm{m}$. The spectral IR dataset and cloud-detection algorithm are detailed by Town et al. (2005). Clouds are detected by how much the IR "window" $(10-12 \mu \mathrm{m})$ is filled in by downwelling radiation from clouds. Each monthly mean $C_{\text {PAERI }}$ is based on 1000-2000 determinations of cloud or no-cloud averaged over a month. The $C_{\mathrm{PAERI}}$ is very sensitive to thin clouds. Adding or subtracting the equivalent of a thin layer of near-surface ice crystals to the cloud/no-cloud threshold to every observation in a month can change the monthly mean $C_{\text {PAERI }}$ by $-10 \%$ or $+18 \%$.

One strength of this dataset is its sensitivity to optically thin clouds, a benefit of the IR spectrum from which $C_{\mathrm{PAERI}}$ is retrieved. A weakness of this dataset is its short period of record, just $1 \mathrm{yr}$.

\section{c. Cloud cover from satellites}

\section{1) International Satellite Cloud Climatology Project}

Monthly mean $C_{\mathrm{ISCCP}}$ presented here is obtained from the ISCCP D2 dataset. A general description of 
the ISCCP project is given by Schiffer and Rossow (1983). The cloud-detection algorithms are detailed by Rossow and Garder (1993a). Changes made to the ISCCP C series data products to produce the D series are given by Rossow and Schiffer (1999). The clouddetection algorithm was validated by Rossow and Garder (1993b), and the D2 dataset has been compared to numerous other satellite products (e.g., Pavolonis and Key 2003; Thomas et al. 2004). ISCCP D2 data products include, but are not limited to, cloud fraction, cloud pressure, cloud-top temperature, cloud optical depth, and cloud water path.

The ISCCP D2 dataset uses AVHRR data poleward of $60^{\circ}$. It uses two channels for cloud detection: a visible channel at $0.65 \mu \mathrm{m}$ and an IR channel at $11 \mu \mathrm{m}$. The visible channel is employed when the sun is higher than $9^{\circ}$ above the horizon (November-February at the South Pole); otherwise, the cloud-detection algorithm depends solely on the IR channel. The cloud-detection algorithms are based on spatial and temporal variations and absolute thresholds in albedo and brightness temperature. For a pixel to be considered cloudy it must be significantly colder than the warmest pixel in a given spatial domain. It must also exhibit variability greater than a set threshold over a 3-day period. The D2 dataset consists of average values on a $250-\mathrm{km}$ equalarea grid; the values given are averages of all pixels within a grid box.

The D2 dataset is composed of monthly averages from 1983 to 2004. We use data from 1994 to 2003 to match the surface-based broadband IR record (section $2 \mathrm{~d}$ ). Over the South Pole $C_{\mathrm{ISCCP}}$ is an average of the three grid boxes centered around the South Pole at $88.5^{\circ} \mathrm{S}$. Uncertainty in $C_{\mathrm{ISCCP}}$ is estimated as being approximately $10 \%$ (Rossow and Garder 1993b), resulting from errors in clear-sky radiances. A further $15 \%-$ $25 \%$ low bias over the polar regions during summer and a $10 \%$ high bias during winter, based on comparison of the D2 dataset to visual observations, is expected (Rossow and Schiffer 1999).

Strengths of the ISCCP dataset are its regular sampling frequency and its spatial coverage. The latter strength will not be exploited in this work; rather, $C_{\text {ISCCP }}$ will be evaluated over the South Pole only. Weaknesses of this dataset are that it uses at most two of the currently available channels, and that near the Poles it must attempt to detect clouds over snow and ice.

\section{2) Extended AVHrR Polar Pathfinder DATASET}

Monthly mean $C_{\mathrm{APP}-\mathrm{x}}$ is calculated from the University of Wisconsin APP-x cloud product dataset. APP-x has been used in a number of studies both in the Arctic and the Antarctic to generate cloud climatologies, estimate cloud radiative forcing, and improve forecast models (e.g., Wang and Key 2003; Pavolonis and Key 2003; Pavolonis et al. 2004; Wang and Key 2005a,b).

The APP-x dataset is presented on a $25-\mathrm{km}$ polar stereographic grid. It uses all available channels of the AVHRR (at $0.65,0.86,3.75,11$, and $12 \mu \mathrm{m}$ ) to identify clouds and derive climate parameters such as surface temperature, surface albedo, cloud fraction, cloud optical depth, cloud-top temperature, cloud phase, precipitable water, and cloud radiative forcing. All quantities are reported at 0200 and 1400 LT. Key (2002) describes the cloud-detection algorithm and extended data products in detail. We expect $C_{\mathrm{APP}-\mathrm{x}}$ to underestimate cloud cover during spring and summer and yield higher amounts of cloud cover during winter because of its sensitivity to near-surface ice crystals (diamond dust) based on previous comparisons of cloud cover in the Arctic (Meier et al. 1997), although diamond dust clouds are typically much more optically thin over the Antarctic interior than over the Arctic.

The monthly means we display from APP-x are averages of the four grid boxes south of $89.8^{\circ} \mathrm{S}$. However, we also determined the $C_{\mathrm{APP}-\mathrm{x}}$ time series as an average of all grid boxes south of $89^{\circ} \mathrm{S}$ (60 grid boxes); it differed insignificantly from that of the four southernmost grid boxes.

Strengths of this dataset are the multiple channels used in its cloud-detection algorithm, its regular sampling frequency, and its spatial coverage. Like ISCCP, its view is from above, so it must deal with the difficulty of detecting clouds over snow and ice. This algorithm has been optimized for polar climates (Key 2002).

\section{d. Cloud cover from surface-based pyrgeometer measurements}

We introduce another cloud cover dataset based on retrievals from surface-based pyrgeometer measurements, $C_{\mathrm{pyr}}$. The ESRL-GMD, formerly known as the Climate Monitoring and Diagnostics Laboratory (CMDL), operates a baseline atmospheric monitoring site at the South Pole. Upward- and downward-looking Eppley pyrgeometers have been deployed there to monitor the longwave radiation budget. The ESRLGMD station is part of the Baseline Surface Radiation Network (BSRN; Ohmura et al. 1998). The data have 3-min temporal resolution from 1994 through 1997 and 1-min temporal resolution from 1998 through 2003. Uncertainties in Eppley pyrgeometer measurements have been characterized at mid- (Philipona et al. 2001) and high latitudes (Marty et al. 2003). We use an operational uncertainty of $8 \mathrm{~W} \mathrm{~m}^{-2}$ for the pyrgeometer 


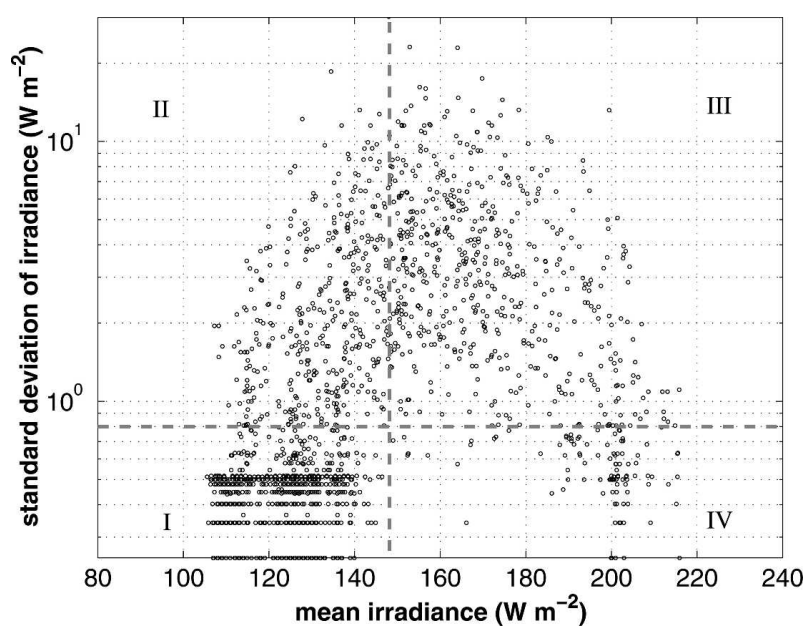

FIG. 2. Scatterplot of standard deviation of downward irradiance over a 20-min time period plotted against mean downward irradiance for the same time period for December 2001. The thresholds of irradiance and standard deviation of irradiance are described in the text. Quadrant I represents the clear-sky observations; observations in all other quadrants are classified as overcast for this month.

measurements made at the South Pole (Town et al. 2005).

The $C_{\mathrm{pyr}}$ is retrieved from the routine pyrgeometer measurements by a dual-threshold method. Figure 2 illustrates how this method is employed for December 2001. Figure 2 is a scatterplot of standard deviation over a 20-min period plotted against the mean downward irradiance over the same time period. We use the 20min time period for analysis because it is an acceptable compromise between temporal resolution and a meaningful standard deviation. The dashed vertical line in Fig. 2 is a threshold calculated using a line-by-line radiative transfer model (LBLRTM) (Clough et al. 1992) for clear sky. Clear-sky downwelling irradiance thresholds were calculated for each month based on monthly mean atmospheric profiles as described in Town et al. (2005). To allow for interannual variability in clear-sky downwelling flux and pyrgeometer calibration drift, 22 $\mathrm{W} \mathrm{m}{ }^{-2}$ is added to each monthly threshold. This tolerance was determined by taking 3 times the annual mean standard deviation of clear-sky irradiance during 2001, where clear skies were determined using the $C_{\text {PAERI }}$ time series. The irradiance data have been inspected to ensure that each monthly irradiance threshold does not encroach on the times of overcast cloud cover. Thus, all data points to the right of the vertical dashed line in Fig. 2, quadrants III and IV, are classified as overcast using the irradiance threshold.

The standard deviation threshold (the horizontal dashed line in Fig. 2) was chosen by inspection of the entire time series of the standard deviation of irradi- ance. Given the absolute irradiance threshold described above, the standard deviation threshold was optimized to a value of $0.8 \mathrm{~W} \mathrm{~m}^{-2}$ to maximize the correlation with the daylight visual estimates of monthly mean cloud cover $\left(r^{2}=0.73\right)$, and minimize the mean residual $(-4.5 \%)$ and rms difference $(6.1 \%)$ between $C_{\text {pyr }}$ and $C_{\text {vis }}$. Slightly smaller mean residual and rms difference with a slightly lower $r^{2}$ were achieved with a threshold of $0.7 \mathrm{~W} \mathrm{~m}^{-2}$. The differences in $C_{\mathrm{pyr}}$ using the two different standard deviation thresholds are within the estimated error of $C_{\mathrm{pyr}}$, discussed below. Therefore, the two standard deviation thresholds of 0.7 and $0.8 \mathrm{~W} \mathrm{~m}^{-2}$ are essentially equivalent. Direct comparisons between the $C_{\text {pyr }}$ and $C_{\text {vis }}$ datasets are presented in section $3 \mathrm{a}$.

The same standard deviation threshold is used for the entire pyrgeometer dataset because there is no reason to suspect that a clear atmosphere during summer will show significantly more radiative variability than during winter. Thus, all data plotted above the horizontal line in Fig. 2, quadrants II and III, are classified as cloudy. In union with the absolute irradiance threshold described previously, the standard deviation threshold essentially prevents thin or patchy clouds from being classified as clear skies.

Pyrgeometers have a hemispheric FOV; therefore, this method classifies the entire sky as being either clear (quadrant I) or overcast (quadrants II, III, and IV) every $20 \mathrm{~min}$. The time series of ones and zeros was averaged for each month to give $C_{\mathrm{pyr}}$. The reason for thinking that a binary method to determine monthly mean cloud cover at South Pole can succeed is that cloud cover there exhibits a U-shaped distribution, with most cases being either clear or overcast (Fig. 1). Figure 1 is for daytime, but it is assumed that clouds exhibit a similar distribution during night, and therefore the dual-threshold method is applied to pyrgeometer data taken for all months.

The frequency of visual reports of sky cover between 2 and 6 octas in Fig. 1 is utilized to determine the bias in our monthly mean $C_{\text {pyr }}$ estimate. Twenty-nine percent of the visual observations in any month are between 2 and 6 octas. Assuming that cases of either 2 or 3 octas are likely misclassified as clear skies, and cases of 4-6 octas are likely misclassified as overcast, the errors resulting from misclassification of partially cloudy skies as clear or overcast almost exactly offset each other in the monthly mean, leaving only a small positive bias of $0.5 \%$, well within the uncertainty of the cloud fraction retrieval. If no skies of 2-3 octas occur in a month, and the rest of the cloud cover distribution is unchanged, then the maximum bias possible is $+5 \%$. Similarly, if no skies of 4-6 octas occur in a month, and the rest of the cloud cover distribution is again un- 
changed, then the maximum negative bias is $-4.5 \%$. The absolute uncertainty in monthly mean $C_{\text {pyr }}$ resulting from the operational uncertainty in the pyrgeometer calibration ( $8 \mathrm{~W} \mathrm{~m}^{-2}$; Town et al. 2005) is $\pm 1 \%$. Thus, interannual variability in monthly mean cloud cover is much larger than the uncertainty or bias in the estimate of an individual monthly mean.

The sensitivity of $C_{\mathrm{pyr}}$ to the standard deviation threshold $\left(0.8 \mathrm{~W} \mathrm{~m}^{-2}\right)$ is greater than the sensitivity of $C_{\mathrm{pyr}}$ to the monthly irradiance threshold. Varying the irradiance threshold by $\pm 5 \mathrm{~W} \mathrm{~m}^{-2}$ has almost no effect on $C_{\mathrm{pyr}}$ during the austral summer but changes $C_{\mathrm{pyr}}$ by $\sim 2 \%-3 \%$ during the austral winter. Increasing the standard deviation threshold from 0.8 to $1 \mathrm{~W} \mathrm{~m}^{-2}$ decreases the annual mean $C_{\mathrm{pyr}}$ by $1 \%-2 \%$. However, decreasing the standard deviation threshold to $0.5 \mathrm{~W}$ $\mathrm{m}^{-2}$ increases the annual mean $C_{\mathrm{pyr}}$ by $20 \%-25 \%$. Because of the greater frequency of optically thin clouds during winter, $C_{\mathrm{pyr}}$ is more sensitive to both thresholds then.

Other methods using threshold methods have been developed for estimating cloud fraction based on surface temperature, relative humidity, and pyrgeometer irradiance (Marty and Philipona 2000; Dürr and Philipona 2004; Sutter et al. 2004). However, those methods are not suitable for the extreme conditions at the South Pole because the surface inversion often decouples the free troposphere from the boundary layer, making surface meteorological variables such as temperature and humidity inadequate indicators of cloud cover. Instantaneous cloud fraction cannot be otherwise estimated from the irradiance measurements because cloud temperature and emissivity would have to be known instantaneously.

\section{Intercomparisons, seasonal cycles, and trends in cloud cover}

In this section we present intercomparisons between the five different cloud cover datasets. We then use results of these intercomparisons to analyze the seasonal cycles and trends derived from the datasets.

\section{a. Intercomparisons}

We begin with the surface-based estimates of cloud cover. Figure 3 shows a scatterplot of monthly mean $C_{\mathrm{pyr}}$ versus monthly mean $C_{\mathrm{vis}}$, during both day (gray circles) and night (black crosses). The correlation is good when there is adequate light, but is poor during the polar night. The wintertime low bias in the visual observations noted by Hahn et al. (1995) is also apparent in Fig. 3. However, the magnitude of the low bias is much greater than expected based on the moonlight correction applied to South Pole surface observations

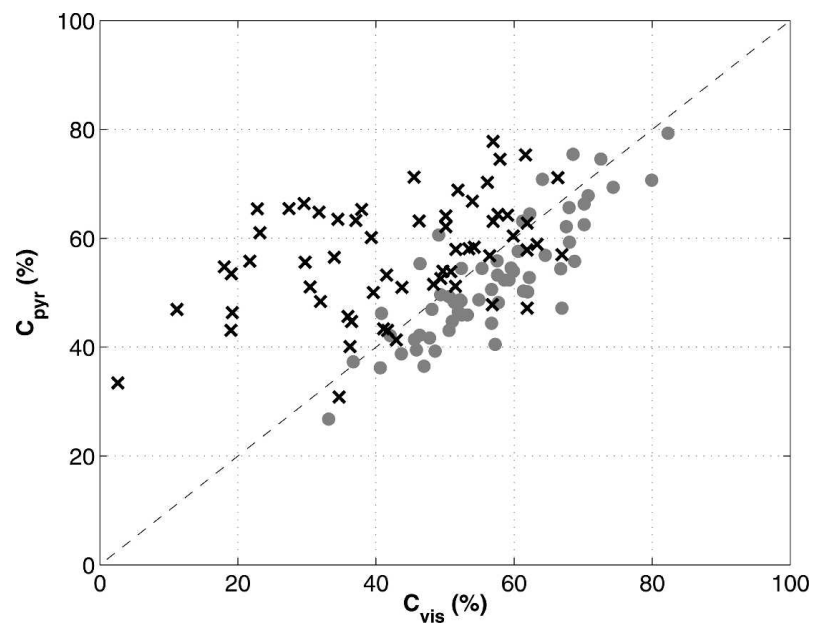

FIG. 3. Scatterplot of monthly mean $C_{\mathrm{pyr}}$ vs monthly mean $C_{\mathrm{vis}}$ for 1994-2003. The circles indicate daylight months (OctoberMarch); the crosses indicate the months of darkness (AprilSeptember). The daytime monthly means are well correlated, $r^{2}=$ 0.73 . The nighttime estimates of $C_{\mathrm{pyr}}$ and $C_{\text {vis }}$ are nearly uncorrelated. The extremely low $C_{\text {vis }}$ value (3\%) is from July 1994.

in Hahn et al. (1995). Our results show that the magnitude of the low bias varies substantially from year to year due in large part to changes in the observer staff, which makes correction of the visual observation climatology problematic. This is discussed further in section $3 b$.

We also compare monthly mean $C_{\text {pyr }}$ to monthly mean $C_{\text {PAERI }}$ and $C_{\text {vis }}$ for 2001 (Fig. 4). As stated earlier, the PAERI collects spectral infrared data with a narrow FOV. Also, $C_{\text {PAERI }}$ is based on a binary method, but the narrow FOV of the PAERI frees the

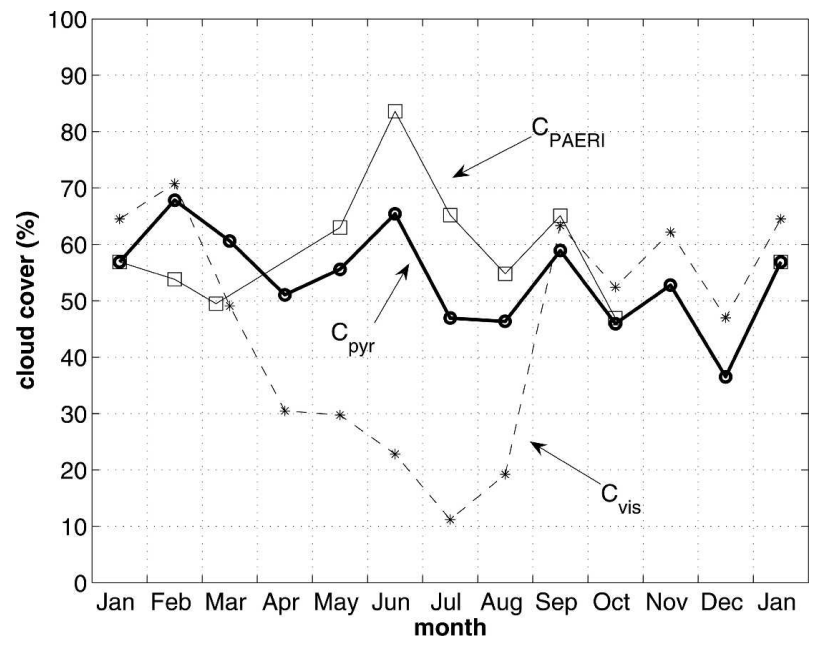

FIG. 4. The seasonal cycle of monthly mean $C_{\mathrm{vis}}, C_{\mathrm{pyr}}$, and $C_{\text {PAERI }}$ for 2001. The algorithm to determine $C_{\text {PAERI }}$ is given in Town et al. (2005). The timing of the $C_{\text {PAERI }}$ point during March is explained in Town et al. (2005). The discrepancy between $C_{\text {PAERI }}, C_{\text {vis }}$, and $C_{\text {pyr }}$ during February is explained in the text. 
retrieval of $C_{\text {PAERI }}$ from the environmental constraint of a U-shaped distribution of cloud cover. Clouds over the South Pole will not preferentially avoid the FOV of the PAERI, allowing monthly means of cloud cover between $C_{\mathrm{vis}}, C_{\mathrm{pyr}}$, and $C_{\mathrm{PAERI}}$ to be considered essentially equivalent spatial and temporal means derived from different measurement techniques.

During the daytime $C_{\mathrm{pyr}}$ compares well with the visual observations, and throughout the winter of 2001 compares well with $C_{\text {PAERI }}$. The year 2001 had a particularly low bias in $C_{\text {vis }}$ during the polar night. The $C_{\mathrm{pyr}}$ is biased low relative to $C_{\mathrm{PAERI}}$ during the winter because $C_{\mathrm{PAERI}}$ is more sensitive to optically thin clouds than $C_{\text {pyr }}$. The discrepancy between $C_{\text {PAERI }}$ and $C_{\mathrm{pyr}}$ during February is due to the fact that in February the PAERI was employed in other activities in addition to routine observation of the atmosphere. The PAERI was therefore unable to get a sample of cloud cover that was adequate to represent the monthly mean.

A figure similar to Fig. 4 appears in Town et al. (2005, their Fig. 11). The cloud-detection algorithm applied to the pyrgeometer data for 2001 in that work employed only an absolute irradiance threshold. Therefore, it is less sensitive to the thin clouds prevalent over South Pole and misses $5 \%-12 \%$ of the clouds during winter that are detected in $C_{\mathrm{pyr}}$ here. While still biased low relative to $C_{\mathrm{PAERI}}, C_{\mathrm{pyr}}$ here agrees much better with $C_{\text {PAERI }}$ than the cloud cover from pyrgeometer measurements in Fig. 11 of Town et al. (2005) because of the incorporation of the standard deviation threshold.

Because $C_{\mathrm{pyr}}$ agrees well with $C_{\mathrm{vis}}$ during the daylight and $C_{\text {PAERI }}$ throughout 2001, we consider $C_{\text {pyr }}$ accurate enough to be used as ground truth against which yearround retrievals of cloud cover from satellites can be judged. Figure 5 shows scatterplots of $C_{\mathrm{APP}-\mathrm{x}}$ versus $C_{\mathrm{pyr}}$ and $C_{\mathrm{ISCCP}}$ versus $C_{\mathrm{pyr}}$. The black crosses are for April-September ("winter") and the gray circles are for the other 6 months (non-winter). During summer, $C_{\mathrm{APP}-\mathrm{x}}$ is biased high and $C_{\mathrm{ISCCP}}$ is biased low. There is no correlation between $C_{\mathrm{APP}-\mathrm{x}}$ and $C_{\mathrm{pyr}}$ during daylight, but there is a slight correlation between $C_{\mathrm{ISCCP}}$ and $C_{\mathrm{pyr}}$ when the ISCCP dataset employs the visible channel in its algorithm (November-February; filled gray circles). No correlation between $C_{\mathrm{ISCCP}}$ and $C_{\mathrm{pyr}}$ was found during the polar winter, but $C_{\mathrm{ISCCP}}$ does obtain a winter mean that agrees with that of $C_{\mathrm{pyr}}$. While $C_{\mathrm{APP}-\mathrm{x}}$ has some skill at estimating monthly mean cloud cover during the winter, the correlation is low $\left(r^{2}=0.12\right)$.

It is currently believed that the cloud bases over the South Pole are often within 1-2 km of the surface (Mahesh et al. 2005). During winter, this would often make the clouds significantly warmer than the surface because of the persistent strong surface-based tempera-
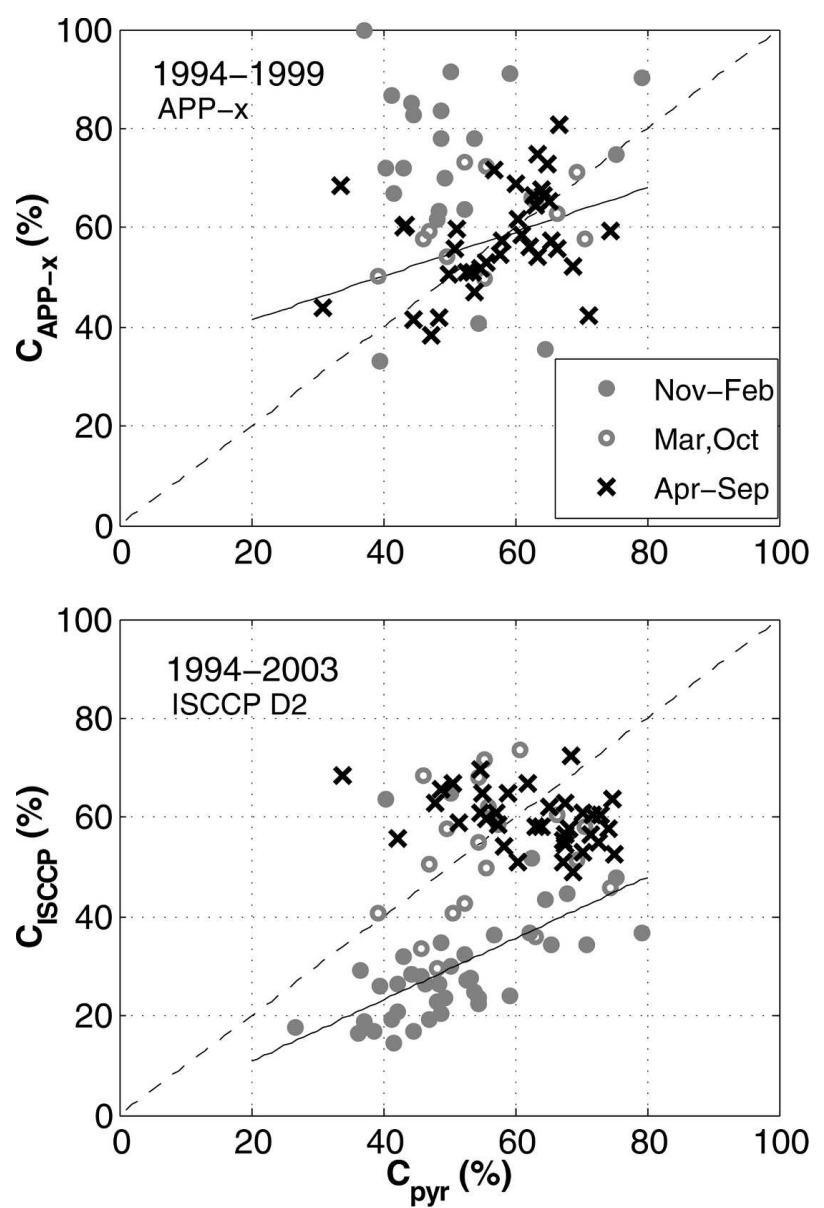

FIG. 5. (top) A scatterplot of monthly mean $C_{\mathrm{APP}-\mathrm{x}}$ vs $C_{\mathrm{pyr}}$ for 1994-99. The gray circles are for cloud cover during daytime, and the black crosses are for nighttime. The filled-in gray circles are for November-February, the open gray circles are for March and October. The uncertainty-weighted regression with $1 \sigma$ errors of the nighttime data (solid line) is slope $=0.4 \pm 0.2$, intercept $=$ $36 \pm 11, r^{2}=0.12$. (bottom) A scatterplot of monthly mean $C_{\mathrm{ISCCP}}$ vs $C_{\mathrm{pyr}}$ for 1994-2003. Symbols are the same as above. The uncertainty-weighted regression with $1 \sigma$ errors of the November-February data is slope $=0.6 \pm 0.2$, intercept $=-2 \pm 9$, $r^{2}=0.22$.

ture inversion. The APP-x algorithm is theoretically capable of identifying a cloud that is warmer than the surface (Key 2002). However, in section $4 \mathrm{c}$ we will see the skill of the APP-x cloud mask is limited by the similarity in spectral emissivity of clouds and snow and the radiative equilibrium reached between clouds and the snow surface.

The mean rms difference between $C_{\mathrm{APP}-\mathrm{x}}$ and $C_{\mathrm{pyr}}$ (not shown) is approximately $10 \%$ during winter. The rms difference grows to $25 \%-30 \%$ during the end of spring through the beginning of fall. This is likely due to solar heating of the surface and the subsequent destruction of the temperature inversion. The rms difference time series of $C_{\mathrm{ISCCP}}$ and $C_{\mathrm{pyr}}$ is similar to that of $C_{\mathrm{APP}-\mathrm{x}}$ 
and $C_{\mathrm{pyr}}$. The rms difference between $C_{\mathrm{ISCCP}}$ and $C_{\mathrm{pyr}}$ grows during the summer because of ISCCP's underestimates of cloud cover during those months. It is unclear why $C_{\text {ISCCP }}$ and $C_{\text {pyr }}$ have a low rms difference during winter; they are uncorrelated during this time.

Nearly identical results for the top panel in Fig. 5 are achieved if we use every grid box in the APP-x dataset south of $89^{\circ} \mathrm{S}$ (60 grid boxes), as opposed to the four grid boxes used to determine $C_{\mathrm{APP}-\mathrm{x}}$. From this we conclude that the reason for the lack of correlation between $C_{\mathrm{pyr}}$ and $C_{\mathrm{ISCCP}}$ during winter is not due to spatial resolution. Further evidence for this conclusion is inferred from the U-shaped distribution of cloud cover over the South Pole (Fig. 1). Because it is clear or overcast $71 \%$ of the time, low-resolution satellite data should yield roughly the same results as the high-reslution satellite data, particularly in the monthly mean.

It is also uncertain what inversion strength would be necessary for the APP-x or ISCCP cloud-detection algorithms to succeed operationally in the future over the Antarctic ice sheet. Estimates of equilibrium clear-sky surface temperatures from station data or theoretical models would aid the development of clear-sky radiance thresholds. In terms of meteorological parameters, the thresholds will be some function of cloud temperature, cloud optical thickness, and clear-sky surface temperature. The South Pole has an average inversion strength of about $25 \mathrm{~K}$ during the winter (Hudson and Brandt 2005). It is believed that many of the clouds over the South Pole reside at the top of the temperature inversion (Mahesh et al. 2001, 2005).

Based on the intercomparison between $C_{\mathrm{vis}}, C_{\text {PAERI }}$, $C_{\mathrm{APP}-\mathrm{x}}, C_{\mathrm{ISCCP}}$, and $C_{\mathrm{pyr}}$, we believe that $C_{\mathrm{pyr}}$ adequately represents cloud cover over the South Pole throughout the year. As stated above, it is well correlated with $C_{\text {vis }}$ during the daylight, when $C_{\text {vis }}$ is known to be accurate. The results of $C_{\mathrm{pyr}}$ agree well with $C_{\text {PAERI }}$ for the entire 2001 SPARCLE record. We therefore consider $C_{\mathrm{pyr}}$ to be the best surface-based cloud cover time series for the South Pole to date and rely primarily on $C_{\text {pyr }}$ to determine the true seasonal cycle and trends in cloud cover in the following subsections. Also, $C_{\text {pyr }}$ is used to find relationships between cloud cover and meteorological parameters in section 4 . The following subsections do, however, include some analysis of the other datasets for intercomparison purposes.

\section{b. Seasonal cycles}

Figure 6 shows the seasonal cycles of $C_{\mathrm{pyr}}$ and $C_{\mathrm{vis}}$, averaged over 1994-2003. The error bars represent interannual variability in cloud cover (one standard deviation). Interannual variability in $C_{\mathrm{pyr}}$ is due primarily

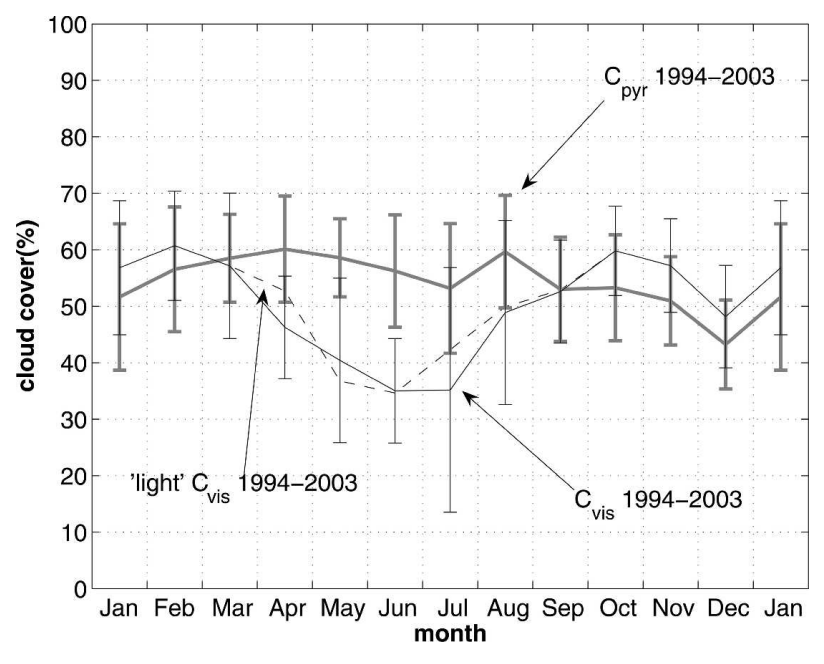

FIG. 6. Seasonal cycles of $C_{\mathrm{pyr}}$ and $C_{\mathrm{vis}}$ based on data from 1994 through 2003. The error bars indicate one standard deviation of the individual monthly means about the multiyear mean for that month; $C_{\text {vis }}$ is determined from the $\mathrm{SO}$ archive for this time period for reasons explained in the text. The dashed line ("light" curve) results from averaging a subset of the observations screened by the illumination criterion of Hahn et al. (1995).

to natural variability, because the pyrgeometer calibration has been stable during the measurement period (E.G. Dutton 2004, personal communication). Interannual variability in $C_{\mathrm{vis}}$ is larger than in $C_{\mathrm{pyr}}$, particularly during winter, due not only to natural variability but also to differences among observers in their interpersonal calibration and their ability to detect thin clouds at night.

As seen earlier (Fig. 3), there is a low wintertime bias in $C_{\text {vis. }}$. The visual observations in Fig. 6 were screened for adequacy of moonlight using the method described Hahn et al. (1995), but this does not seem to improve the wintertime estimates of cloud cover significantly relative to $C_{\text {pyr }}$. The values for the sunlit months are averages of approximately 1240 observations each. The months of May, June, and July each contain about 280 observations after application of the illumination criterion.

Not every winter shows the same low bias, as indicated by the large wintertime error bars. Based on this, we believe it is possible for visual observers to estimate monthly mean $C_{\text {vis }}$ during night under adequate moonlight with only a small low bias if the observers are diligent; they must learn the constellations of the night sky and allow themselves to become dark-adapted prior to each observation. The accuracy of monthly mean $C_{\text {vis }}$ is subject to not only the skill of the observers but also to whether the time period of adequate moonlight is representative of the true monthly mean cloud cover. However, even though we believe it is possible for vi- 


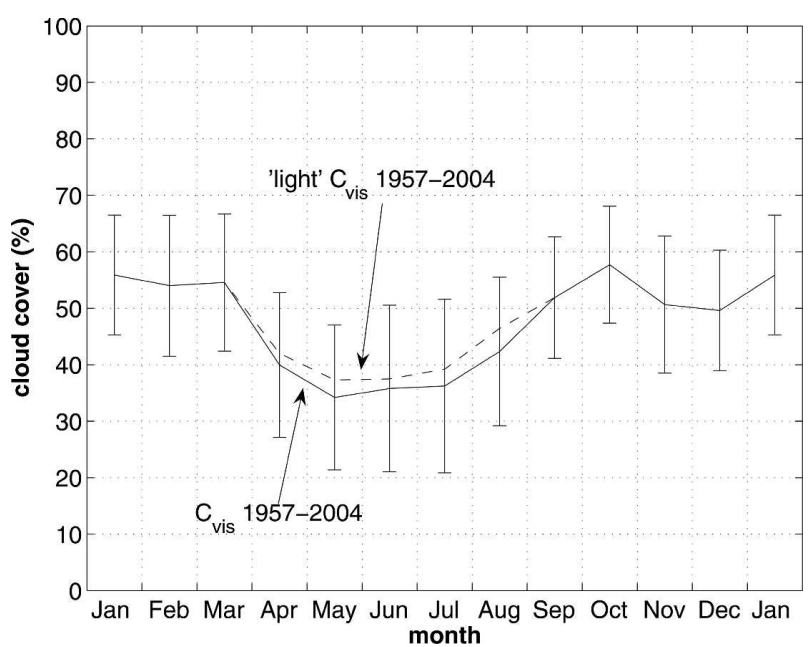

FIG. 7. The $C_{\text {vis }}$ estimate daily averages from 1957 through 2004. The dashed line ("light" curve) results from averaging a subset of the observations screened by the illumination criterion of Hahn et al. (1995).

sual observers to make estimates of cloud cover with only a small low bias during the polar night, the current wintertime record of $C_{\mathrm{vis}}$ is still biased significantly low even after the moonlight correction.

The seasonal cycle of $C_{\text {vis }}$ for the 48 yr of 1957-2004 is shown in Fig. 7. For this dataset screening for adequate moonlight consistently increases the monthly mean $C_{\text {vis }}$ during the winter months by approximately $3 \%$. However, this is still not sufficient to bring about agreement with $C_{\mathrm{pyr}}$. In addition, the standard deviations about the monthly means in Fig. 7 are still greater during winter than those about $C_{\mathrm{pyr}}$ in Fig. 6. [The moonlight criterion of Hahn et al. (1995) was developed using cloud reports from latitude zones of $10^{\circ}-$ $50^{\circ} \mathrm{N}$, where the clouds are thicker on average than over the interior of Antarctica.]

Ultimately, we use $C_{\mathrm{pyr}}$ to estimate the lower end of the range of the true monthly mean cloud cover; $C_{\mathrm{vis}}$ is used to estimate the higher end. We assume that the low bias in $C_{\mathrm{pyr}}$ relative to $C_{\mathrm{vis}}$ during daylight is still present during the night, so we add $5 \%$ to $C_{\mathrm{pyr}}$ during the winter in estimating the true wintertime cloud cover. Thus, the three cloud cover datasets presented in Figs. 6 and 7 show that the overall seasonal cycle in cloud cover has a minimum in November and December of $45 \%-50 \%$, and a plateau from March through October of $55 \%-65 \%$.

We next present the seasonal cycle of cloud cover as derived from the ISCCP and APP-x datasets (Fig. 8) for comparison with the other cloud cover datasets. We find the shape of the seasonal cycle of $C_{\mathrm{ISCCP}}$ to be consistent with the seasonal cycle of $C_{\mathrm{pyr}}$ in that cloud cover is greater in winter than in summer, but the win-

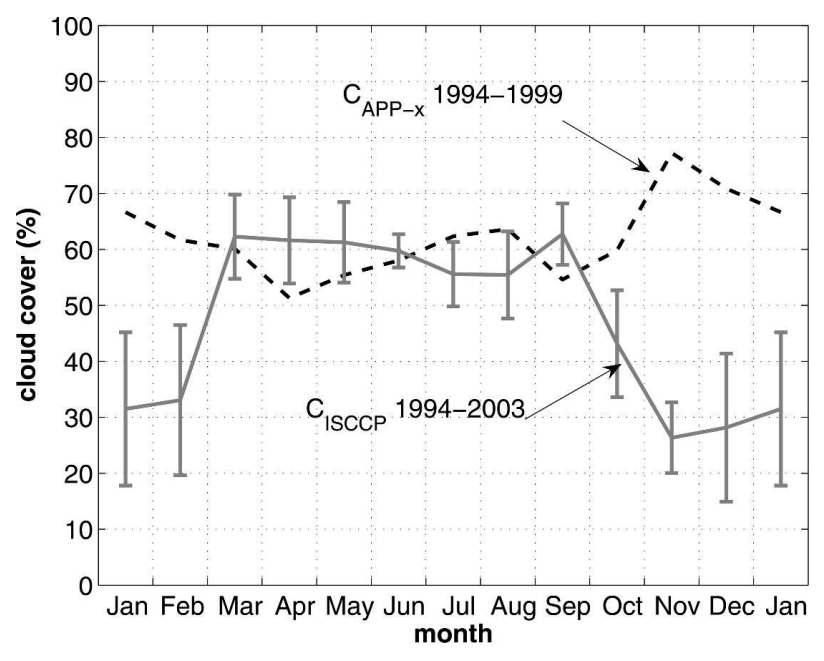

FIG. 8. Seasonal cycle of monthly mean $C_{\text {ISCCP }}(1994-2003)$ and $C_{\mathrm{APP}-\mathrm{x}}(1994-99)$. Error bars on $C_{\mathrm{ISCCP}}$ are $1 \sigma$ of the composite monthly mean for 1994-2003. No error bars were computed for $C_{\mathrm{APP}-\mathrm{x}}$ because of the short length of the time series.

ter-summer difference in $C_{\text {ISCCP }}$ is much greater than in $C_{\mathrm{pyr}}$. The wintertime mean from $C_{\mathrm{ISCCP}}$ agrees with $C_{\mathrm{pyr}}$. The wintertime mean of $C_{\mathrm{APP}-\mathrm{x}}$ agrees with $C_{\mathrm{pyr}}$ based on the results shown in the top panel of Fig. 5, but $C_{\mathrm{APP}-\mathrm{x}}$ overestimates cloud cover relative to $C_{\mathrm{pyr}}$ during the short summer, contrary to expectations based on Meier et al. (1997), but consistent with the results of Maslanik et al. (2001).

\section{c. Trends}

Table 2 shows trends computed from the visual and pyrgeometer time series. In all seasons except summer $C_{\mathrm{pyr}}$ shows decreasing trends, but none of the trends are significant. For the same time period (1994-2003) $C_{\text {vis }}$ shows a significant increasing trend in mean annual cloud cover, which is dominated by the dubious wintertime trend. For spring, summer, and autumn, although the trends are mostly insignificant, the signs and approximate magnitude of the trends of $C_{\mathrm{vis}}$ do agree with those of $C_{\mathrm{pyr}}$.

The trends in $C_{\text {vis }}$ for 1957-2004 are reported for the sunlit months. The winter trends, and therefore annual trends, are not reliable due to the low wintertime bias in visual observations. The long-term trends in the other seasons may be affected by changes in observing practices resulting from changes in the SPMO contractor. On the whole, we trust the historical daytime visual observations. A topic for further investigation is the effects of changes in SPMO contractor on seasonal trends.

Figure 9 shows the time series of seasonal averages for $C_{\text {vis }}$ (thin curve) and $C_{\text {pyr }}$ (thick curve). Variability in the low wintertime bias in $C_{\mathrm{vis}}$ is apparent in contrast 
TABLE 2. Annual and seasonal trends in cloud cover for 1957-2004 and 1994-2003 in percentage points per decade (\% decade $\left.{ }^{-1}\right)$. The number in parentheses is one standard deviation of the slope of the trend. The trends from visual observations $\left(C_{\mathrm{vis}}\right)$ and pyrgeometer measurements $\left(C_{\mathrm{pyr}}\right)$ in bold are statistically significant to $1 \sigma$. We do not report the winter or annual trends in $C_{\mathrm{vis}}$ because of the uncertainties associated with $C_{\text {vis }}$ during winter. All trends in the visual observations may be a result of changes in observing practices resulting from changes in SPMO contractor. The seasons at the South Pole are defined here as spring $=$ October-November, summer $=$ December-January, autumn $=$ February-March, and winter $=$ April-September. The reason for the unorthodox seasonal definitions can be seen in the annual 2-m temperature cycle in Fig. 14.

\begin{tabular}{lcrrrr}
\hline \hline & Annual & Spring & Summer & Autumn & Winter \\
\hline$C_{\text {pyr }} 1994-2003$ & $-1.6(3.4)$ & $-3.5(6.7)$ & $7.5(8.7)$ & $-6.1(7.4)$ & $-1.9(4.5)$ \\
$C_{\text {vis }} 1994-2003$ & & $-5.1(6.0)$ & $\mathbf{8 . 8}(8.2)$ & $-1.3(8.4)$ & $\mathbf{3 . 6 ( 0 . 9 )}$ \\
$C_{\text {vis }} 1957-2004$ & & $\mathbf{2 . 6}(0.8)$ & $\mathbf{1 . 1}(0.8)$ & \\
\hline
\end{tabular}

with the $C_{\mathrm{pyr}}$ data from 1994 to 2003. Interannual variability in the seasonal averages is approximately the same for each season, also shown in Fig. 6. It is apparent that the time series of $C_{\mathrm{pyr}}$ and $C_{\mathrm{vis}}$ are correlated for all seasons that have some sunlight (spring, summer, autumn), but are uncorrelated in winter.

\section{Cloud cover and other meteorological parameters at the South Pole}

We now examine the relationship between $C_{\mathrm{pyr}}$ and radiative fluxes, $10-\mathrm{m}$ wind speed and direction, and 2-m temperature. All of the routine observations used here were provided to us by the ESRL-GMD.
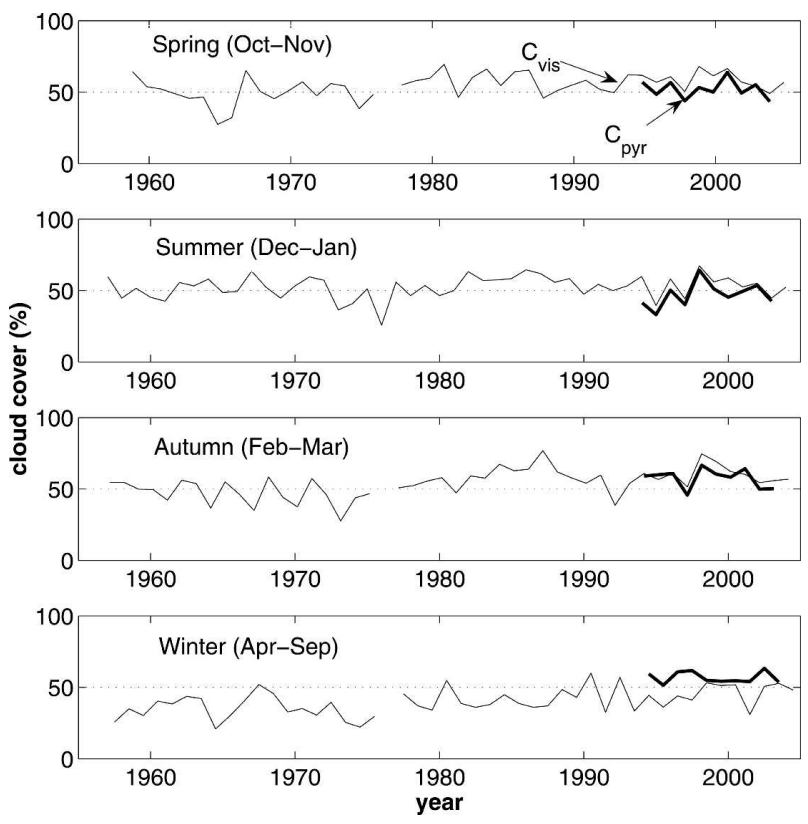

FIG. 9. Time series of cloud cover by season. The thin curve is $C_{\text {vis }}$ (1957-2004); the thick curve is $C_{\mathrm{pyr}}$ (1994-2003). The trends in the visual observations may be a result of changes in observing practices resulting from changes in SPMO contractor. The wintertime trend for $C_{\text {vis }}$ is particularly unreliable; see text for discussion.

\section{a. Longwave cloud radiative forcing}

Longwave fluxes collected by the ESRL-GMD are used here to calculate monthly means, annual means, and trends in longwave downwelling cloud radiative forcing (LDCRF) and longwave net cloud radiative forcing (LNCRF). LDCRF and LNCRF are defined by Eqs. (1) and (2). Here LDF is the longwave downwelling flux and LUF is the longwave upwelling flux. Clear-sky averages were determined using the $C_{\mathrm{pyr}}$ dataset to identify the clear times. We use the definition of cloud radiative forcing from Ramanathan et al. (1989). Clear-sky averages are subtracted from all-sky averages to obtain the net effect of clouds (and the associated changes in temperature and humidity) on the downwelling or net longwave fluxes. Here,

$$
\begin{aligned}
& \mathrm{LDCRF}=\mathrm{LDF}_{\mathrm{all}}-\mathrm{LDF}_{\text {clear }} \\
& \mathrm{LNCRF}=\left(\mathrm{LDF}_{\text {all }}-\mathrm{LUF}_{\text {all }}\right)-\left(\mathrm{LDF}_{\text {clear }}-\mathrm{LUF}_{\text {clear }}\right) .
\end{aligned}
$$

Figure 10 shows seasonal cycles of LDCRF and LNCRF for the South Pole. The error bars indicate interannual variability $(1 \sigma)$. LDCRF has an annual mean of $18 \mathrm{~W} \mathrm{~m}^{-2}$, while LNCRF has an annual mean of $10 \mathrm{~W} \mathrm{~m}^{-2}$. There does not seem to be any significant seasonal variation in LDCRF, but there is a slight seasonal cycle in LNCRF. No significant trends were detected in either quantity for 1994-2003.

Our result of $10 \mathrm{~W} \mathrm{~m}^{-2}$ for the annual LNCRF differs from the results of other workers. Hines et al. (2004) estimated LNCRF $=1 \mathrm{~W} \mathrm{~m}^{-2}$ for 1986-88 at the South Pole using the surface radiation dataset compiled by Dutton et al. (1989). Rather than attempting to identify all clear scenes within a month, Hines et al. (2004) chose the lowest values of LDF and LUF that occurred with the month $\left(\mathrm{LDF}_{\min }, \mathrm{LUF}_{\min }\right)$ and assigned those values to $\mathrm{LDF}_{\text {clear }}$ and $\mathrm{LUF}_{\text {clear }}$. For LNCRF computed using the method of Hines et al. (2004) we will use the symbol LNCRF*. Equation (2) then becomes 


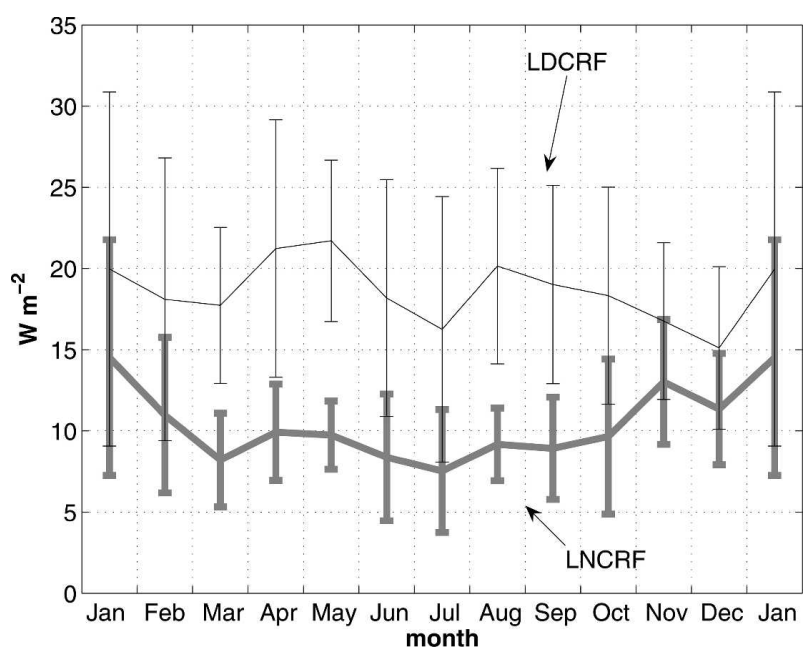

FIG. 10. A seasonal cycle of LDCRF (thin black curve) and LNCRF (thick gray curve) using data from 1994-2003. Error bars are $1 \sigma$ about the composite monthly means for 1994-2003.

$\mathrm{LNCRF}^{*}=\left(\mathrm{LDF}_{\mathrm{all}}-\mathrm{LUF}_{\mathrm{all}}\right)-\left(\mathrm{LDF}_{\mathrm{min}}-\mathrm{LUF}_{\mathrm{min}}\right)$.

Figure 11 illustrates the difference between LNCRF* and LNCRF for the decade of 1994-2003. The annual mean of LNCRF* is approximately $7 \mathrm{~W} \mathrm{~m}^{-2}$. The $\mathrm{LDF}_{\text {clear }}-\mathrm{LUF}_{\text {clear }}$ difference is similar to the $\mathrm{LDF}_{\text {min }}{ }^{-}$ $\mathrm{LUF}_{\text {min }}$ difference during the winter; however, the 10yr mean and interannual variability of monthly mean LNCRF* are not similar to those of LNCRF during the months when insolation becomes significant. In general, the standard deviation about the monthly mean LNCRF* is greater than that of LNCRF, particularly during sunlit months. We believe this is because the shortwave cloud radiative forcing affects surface temperature, and therefore the longwave upwelling flux. The effect of the shortwave cloud radiative forcing is not directly correlated with the longwave cloud radiative forcing because cloud optical depth differs significantly between visible and infrared wavelengths for the same liquid water path, particle size, and phase. Therefore, the relationships between LUF $_{\text {min }}$, clear-sky LUF, and cloudy-sky LUF are more variable when insolation is substantial than when longwave radiation dominates the radiation budget. The range of variability in LNCRF* during sunlit months then explains how Hines et al. (2004) might report an annual mean LNCRF* of $1 \mathrm{~W} \mathrm{~m}^{-2}$ for the 2-yr period recorded by Dutton et al. (1989) when our 10-yr mean is closer to $7 \mathrm{~W} \mathrm{~m}^{-2}$.

We also compute the relationship between LDCRF and cloud cover (Fig. 12). Over the entire 10-yr dataset, LDCRF is related to $C_{\mathrm{pyr}}$ by $0.58 \mathrm{~W} \mathrm{~m}^{-2} \%^{-1}$. This relationship is linear over the range of the monthly

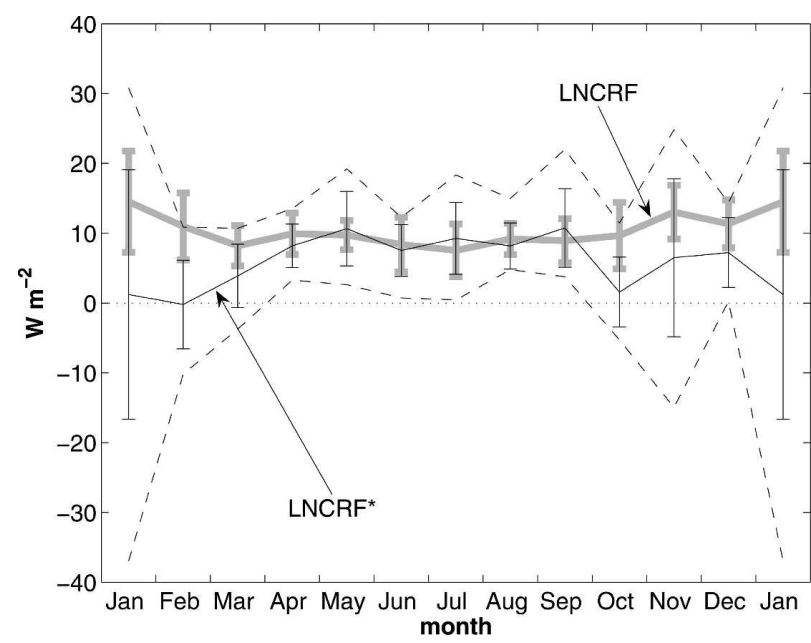

FIG. 11. Comparison of LNCRF and LNCRF* from Eq. (3) for the years 1994-2003. The thin dashed lines are the extreme monthly values of $\mathrm{LNCRF}^{*}$, included to illustrate the effect of solar irradiance on LNCRF*. The method for determining LNCRF* is from Hines et al. (2004).

mean cloud cover we observed, but surely becomes nonlinear as cloud cover decreases below $20 \%-30 \%$ because LDCRF must be zero if cloud cover is zero. The slopes of the different lines are listed in the caption of Fig. 12. This relationship should be useful in future assessments of retrieved and modeled cloud cover over the East Antarctic Plateau. When we consider net forc-

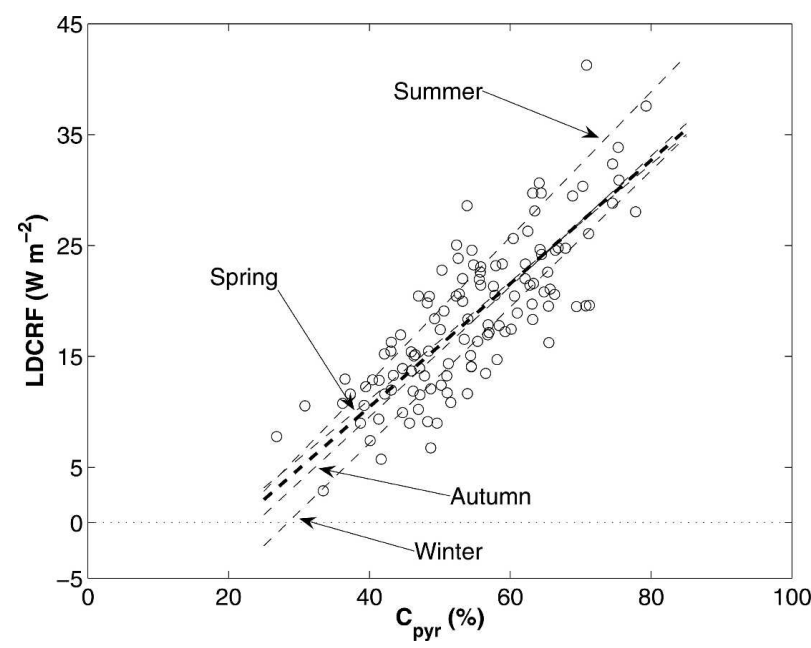

FIG. 12. Relationship between LDCRF and cloud cover $\left(C_{\text {pyr }}\right)$ over the South Pole. The seasons are labeled; the thick dashed line is the annual relationship. The slopes and $1 \sigma$ errors are as follows: annual $=0.6 \pm 0.1 \mathrm{~W} \mathrm{~m}^{-2} \%^{-1}$, summer $=0.7 \pm 0.2 \mathrm{~W}$ $\mathrm{m}^{-2} \%^{-1}$, autumn $=0.6 \pm 0.2 \mathrm{~W} \mathrm{~m}^{-2} \%^{-1}$, winter $=0.6 \pm 0.1 \mathrm{~W}$ $\mathrm{m}^{-2} \%^{-1}$, and spring $=0.5 \pm 0.2 \mathrm{~W} \mathrm{~m}^{-2} \%^{-1}$. Note that none of the seasonal regressions are significantly different from each other or the annual regression. 
ing as opposed to downward forcing, there is little correlation between $\mathrm{LNCRF}$ and $C_{\mathrm{pyr}}$. It seems that the thermal inertia of the snowpack puts enough lag into the system to destroy the correlation of LNCRF with cloud fraction.

We now compare our LNCRF estimates to those derived from satellite data. The annual mean values of LNCRF from ISCCP (16 W m $\left.{ }^{-2}, 1985-93\right)$ and APP-x (30 $\left.\mathrm{W} \mathrm{m}^{-2}, 1982-99\right)$ (Hines et al. 2004) are larger than our estimates of LNCRF. Pavolonis and Key (2003) also found that the ISCCP and APP-x datasets have opposite seasonal cycles in LNCRF. $\mathrm{LNCRF}_{\mathrm{APP}-\mathrm{x}}$ is greatest in summer and least during winter, as we also find (Fig. 10). The mean annual $\mathrm{LNCRF}_{\mathrm{ISCCP}}$ is closer to our results, but it is clear that this must be a coincidence because the $C_{\text {ISCCP }}$ is not adequately correlated with $C_{\text {pyr }}$ to be useful for this application (Fig. 5, bottom panel). However, it is conceivable that these errors are due solely to mismatches of annual average timing.

\section{b. Wind speed and direction}

Cloud cover shows a significant relationship with the wind direction measured at $10 \mathrm{~m}$ (Fig. 13). This is due to the binary nature of weather at the South Pole. During calm periods the Antarctic Plateau falls into an inversion-wind equilibrium where the surface wind results from a balance between gravitational forces along the shallow slope of the plateau, the Coriolis force, and frictional drag across the snow surface (Hudson and Brandt 2005). The other regime commonly experienced at the South Pole is when a synoptic storm is able to reach the Antarctic interior. Resulting from the latitude and the stable near-surface atmosphere, winds spiral counterclockwise with height. Thus, the 10 -m winds are not necessarily in the same direction as the upper-level winds that are responsible for mesoscale advection. Neff (1999) analyzed upper-level winds based on radiosonde soundings and found that even though there are two dominant regimes of surface flow (north-northwest and east-southeast), there are three dominant regimes of upper-level flow. When the upper-level winds are from the east-southeast, the surface winds fall into the inversion wind regime. [Directions at the South Pole are in reference to a grid centered on the South Pole. "North" means parallel to the Greenwich Meridian, in the direction of Greenwich. "South" is in the opposite direction. "East" is in the direction of the Indian Ocean, parallel to $90^{\circ}$ longitude]. The north-northwest 10 -m winds associated with maximum cloud cover correspond to two different upper-level wind regimes-an energetic synoptic flow that spirals to the northnorthwest from the northwest as it approaches the sur-
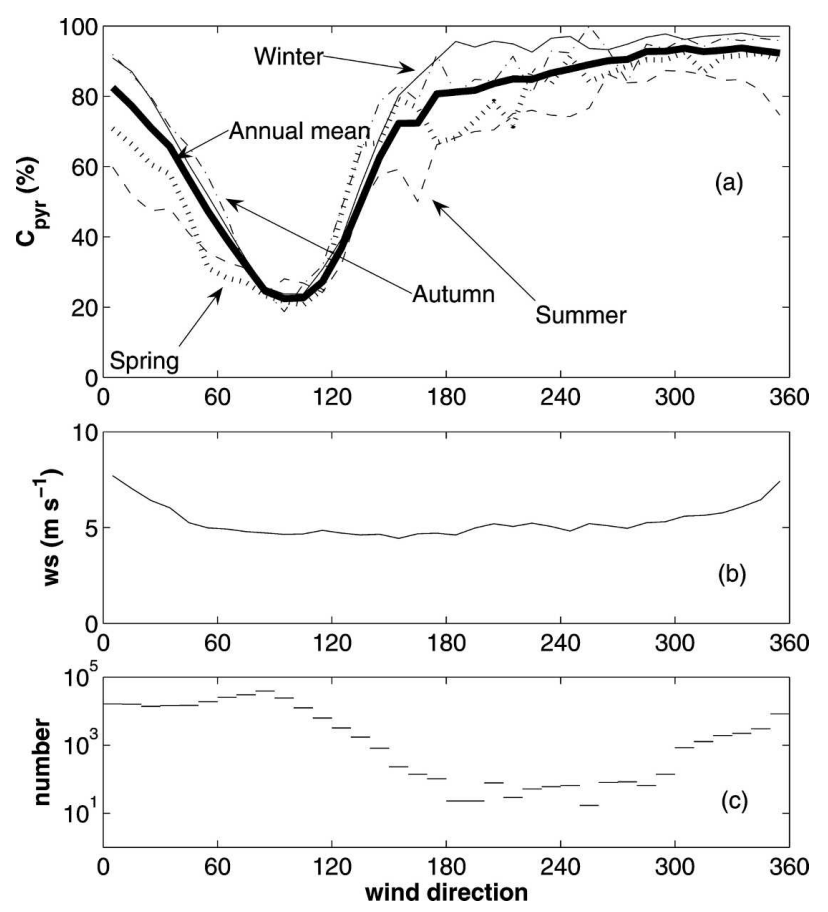

FIG. 13. (a) Mean annual cloud cover $\left(C_{\mathrm{pyr}}\right)$ as a function of 10-m wind direction in $10^{\circ}$ bins for 1994-2003. (b) Mean annual wind speed as a function of $10-\mathrm{m}$ wind direction in $10^{\circ}$ bins for 1994-2003. (c) Frequency of wind direction in $10^{\circ}$ bins for 1994 2003. Directions are referenced to the South Pole grid, where, for example, $0^{\circ}$ is parallel to the Greenwich meridian, in the direction of Greenwich, and $180^{\circ}$ is parallel to the $180^{\circ}$ longitude line, and $90^{\circ}$ is in the direction of the Indian Ocean.

face, and a slightly less energetic synoptic flow from the southwest that must spiral even more to the northnorthwest as it approaches the surface.

The lowest average cloud cover $(25 \%)$ occurs when the $10-\mathrm{m}$ winds are from $60^{\circ}$ to $100^{\circ}$, which is the inversion wind regime. The highest average cloud cover (80\%) occurs when the $10-\mathrm{m}$ winds are from $300^{\circ}$ to $20^{\circ}$, which is the synoptic regime. The pattern of cloud cover is essentially the same in all seasons, but the absolute magnitude varies about $30 \%$ from season to season in the synoptic regime. Figure $13 \mathrm{c}$ shows the frequency of observations for 1994-2003. The near-surface winds almost never come from the $150^{\circ}-300^{\circ}$ sector, which is why the data for this sector in Figs. 13a and 13b are noisy.

The annual average $10-\mathrm{m}$ wind speed is $4.5 \mathrm{~m} \mathrm{~s}^{-1}$ for the inversion wind regime, increasing to $7 \mathrm{~m} \mathrm{~s}^{-1}$ for the synoptic regime (Fig. 13b). The difference is maintained throughout the seasons. The monthly averages in individual years range from 3.5 to $6 \mathrm{~m} \mathrm{~s}^{-1}$ during summer and from 5 to $8.5 \mathrm{~m} \mathrm{~s}^{-1}$ during winter. There is no robust correlation between wind speed and cloud 


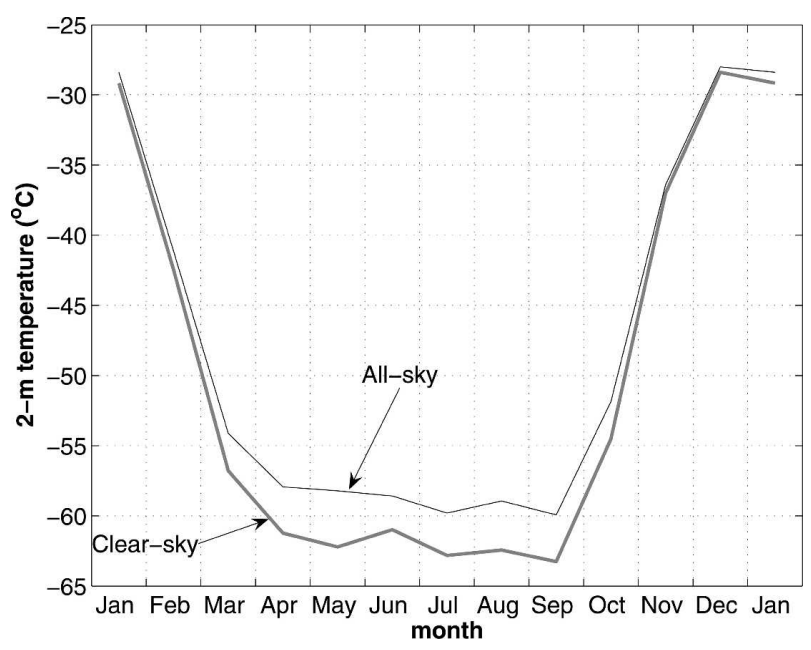

FIG. 14. Seasonal cycle of monthly mean 2-m temperature, using either all observations or only the observations made under clear skies, determined by $C_{\mathrm{pyr}}$, for 1994-2003.

cover, although they are generally related by the same synoptic and topographical influences.

\section{c. Near-surface air temperature}

The annual cycle of 2-m temperature on the East Antarctic Plateau is a peculiar feature of the climate. It has been thoroughly studied (e.g., Dalrymple 1966; Kuhn et al. 1975; Schwerdtfeger 1984; Hudson and Brandt 2005). The seasonal cycle exhibits no welldefined minimum in winter $2-\mathrm{m}$ temperature; this is known as the coreless winter. Figure 14 shows the seasonal cycle of 2-m temperature for the South Pole based on monthly means for 1994-2003 (thin black line). The nearly constant winter temperature results from a balance between sensible and latent heat advection aloft from the coast, longwave downwelling radiation from aloft, near-surface turbulent heat fluxes, subsurface heat fluxes, and thermal emission from the surface to space.

The seasonal cycle of clear-sky 2-m temperature, as determined from $C_{\mathrm{pyr}}$, is shown as the thick gray line in Fig. 14. Times of clear skies are $0.5-1 \mathrm{~K}$ lower than the monthly mean during summer, and 3-4 $\mathrm{K}$ lower than the monthly mean during winter.

The difference between mean all-sky winter temperatures and mean clear-sky winter temperatures can be explained by the magnitude of the LNCRF. The difference in thermal emission of a radiatively black surface at $-63^{\circ} \mathrm{C}$ (the mean clear-sky winter 2-m temperature) and a radiatively black surface at $-59^{\circ} \mathrm{C}$ (the mean all-sky winter 2-m temperature) is approximately $8.6 \mathrm{~W} \mathrm{~m}^{-2}$. This is nearly the same as the annual mean $\mathrm{LNCRF}$ of $10 \mathrm{~W} \mathrm{~m}^{-2}$. Cloud radiative forcing can therefore explain all of the increase in monthly mean 2-m temperature from clear skies to all skies during the winter. Advection of heat and moisture aloft is responsible for maintaining the inversion-top temperature, approximately $400 \mathrm{~m}$ above the surface, at $-35^{\circ} \mathrm{C}$. This large-scale advection provides the energy that the clouds and atmosphere radiate to the surface, raising near-surface atmospheric temperatures.

Based on Fig. 14, it seems that clouds are associated with warmer surface temperatures at the South Pole, as expected. Pavolonis and Key (2003) found a similar result with the APP-x dataset, but we question the basis of the result because of the low accuracy of the APP-x cloud mask. Using a cloud mask algorithm based on AVHRR data, Comiso (2000, his Fig. 5) found that cloud cover over the Antarctic ice sheet has no net effect on surface temperature. That result is in direct disagreement with the results presented in Fig. 14. Specifically, Comiso found that January and July clear-sky monthly mean surface temperature from station data across Antarctica are not significantly colder than the all-sky monthly means for January and July. The clearsky times were identified based on the satellite cloud mask. Comiso also found an excellent correlation between the in situ surface temperatures and those derived from the satellite data.

Based on our comparisons of the APP-x and ISCCP polar cloud masks to the surface-based cloud cover estimates, we believe it is likely that the cloud mask of Comiso (2000) is not able to distinguish between clouds and the snow surface. This explains why Comiso does not find any difference between clear- and all-sky monthly mean surface temperatures as derived from satellite data. The correlation between the January and July satellite-derived surface temperature and the in situ surface temperature is likely due to the emission properties of clouds. A thick cloud will raise the surface temperature by emitting downward as a blackbody while the cloud top becomes the effective emitting surface to space. If the cloud is not "black," then emission to space will be a combination of emission from the cloud and the snow surface. Over the Antarctic Plateau, clouds come into radiative equilibrium with the surface within a few hours (Hudson and Brandt 2005, their Fig. 19); therefore, the cloud temperature is often close to the surface temperature. If not, the sum of the irradiances from cloud and surface will not be far from that of a blackbody at the surface temperature. Thus, estimates of surface temperature in Comiso (2000) probably should be interpreted as estimates of all-sky monthly mean surface temperature rather than as clearsky monthly mean surface temperature. 


\section{Conclusions}

Cloud cover over the South Pole is presented from two satellite-based datasets and three surface-based datasets, for varying time periods. The surface-based cloud cover datasets are from visual observations $\left(C_{\mathrm{vis}}\right)$, a short spectral infrared dataset $\left(C_{\mathrm{PAERI}}\right)$, and routine broadband infrared measurements $\left(C_{\mathrm{pyr}}\right)$. The satellitebased cloud cover datasets are those of APP-x and ISCCP. The estimates of monthly and seasonal cloud cover are intercompared. The best estimate of cloud cover over the South Pole is provided by $C_{\mathrm{pyr}}$ because of its record length and stable calibration. Cloud cover from visual observations is found to have a worse low bias during the polar winter than expected, even after correction for adequate light. Cloud cover from APP-x $\left(C_{\mathrm{APP}-\mathrm{x}}\right)$ has some skill at estimating cloud cover during the winter, but overestimates mean summer cloud cover and is uncorrelated with other estimates of cloud cover during the summer. Cloud cover from ISCCP $\left(C_{\mathrm{ISCCP}}\right)$ is biased low when the sun is more than $9^{\circ}$ above the horizon. While $C_{\mathrm{ISCCP}}$ is uncorrelated with $C_{\mathrm{pyr}}$ during the winter, it obtains the seasonal mean correctly.

The seasonal cycle of cloud cover over the South Pole ranges from a minimum of $45 \%-50 \%$ during the short summer to $55 \%-65 \%$ throughout the autumn, winter, and spring. Insignificant trends were found in $C_{\text {vis }}$ during the 1994-2003 time period, the length of the $C_{\text {pyr }}$ record. However, during this time period the seasonal trends from visual observations do agree with those from pyrgeometer analyses, increasing cloud cover during summer months (December-January) and decreasing cloud cover during spring (OctoberNovember) and autumn (February-March). Their interannual variations are also correlated. The longest period of record is that of the visual observations (1957-2004), and significant increasing trends are found in $C_{\text {vis }}$ for spring, summer, and autumn. However, changes in observer practices have probably contributed to these trends, a possibility that requires further investigation.

The relation of clouds with surface meteorology was investigated. The mean annual longwave downwelling cloud radiative forcing is approximately $18 \mathrm{~W} \mathrm{~m}^{-2}$, with no seasonal cycle. The mean annual longwave net cloud radiative forcing is approximately $10 \mathrm{~W} \mathrm{~m}^{-2}$, with a seasonal cycle ranging from $14 \mathrm{~W} \mathrm{~m}^{-2}$ during summer to $8 \mathrm{~W} \mathrm{~m}^{-2}$ during winter. The $C_{\mathrm{pyr}}$ shows significant and consistent variability with surface wind speed and direction, which is related to synoptic flow over the East Antarctic Plateau. Near-surface air temperature is raised by the presence of clouds- $0.5-1 \mathrm{~K}$ during the summer and 3-4 $\mathrm{K}$ during the winter.

We believe that evaluating the cloud mask is an efficient means by which to improve satellite retrievals. If the satellite algorithms are unable to reliably estimate cloud fraction, then cloud properties (e.g., cloud optical depth, cloud-top temperature, cloud-top pressure, phase) and other products that depend on the accuracy of the cloud mask (e.g., surface temperature, surface radiative fluxes, cloud forcing) are also suspect. Unfortunately, false positive results are possible when comparing derived properties (surface albedo, cloud radiative forcing), because of potential offsetting errors in the derived properties, especially when dealing with clouds over snow and ice. Comparison of the results presented here to surface temperature retrievals from space, together with our other analyses, lead us to conclude that the APP-x and ISCCP cloud masks are probably not yet able to adequately identify clouds over the East Antarctic Plateau. Newer sensors, like the Moderate Resolution Imaging Spectroradiometer (MODIS) and Multiangle Imaging Spectroradiometer (MISR), offer promise in cloud detection but do not yet have a long enough record for climatic studies. Satellite measurements in the infrared window $(11 \mu \mathrm{m})$ are likely useful in determining monthly mean all-sky, rather than clear-sky, surface temperature because of the similar spectral emissivity of snow and clouds and the radiative equilibrium established between clouds and the underlying snow surface.

We recommend this dataset of cloud cover and cloud radiative forcing for use in other evaluations of satellite retrievals and polar models. Routine surface-based broadband infrared measurements may be used to estimate cloud cover based on simple irradiance and standard deviation thresholds. This method may be useful in situations where observation of clouds is compromised by extreme climates or availability of manpower. The method employed here using routine pyrgeometer measurements will probably succeed only where instantaneous cloud fractions exhibit a U-shaped distribution. However, infrared measurements made with a narrow field of view are not subject to this restriction.

Acknowledgments. Stephen Hudson helped to collect the SPARCLE dataset, and provided advice and technical assistance. Many ESRL and NOAA employees were involved in collecting the ESRL data at the South Pole. Bryan Johnson, Thomas Mefford, and Ellsworth Dutton provided the data and metadata from the ESRL. Ellsworth Dutton provided information about the maintenance and calibration of the pyrgeometer. Keith Hines provided some cloud forcing data. Jeffrey 
Key and Michael Pavolonis provided us with the APP-x dataset. The Space Science and Engineering Center at University of Wisconsin provided the archived South Pole meteorological data. Kathie Hill provided information about the South Pole meteorological data. This work was supported by NSF Grants OPP-9726676 and OPP-0230466.

\section{REFERENCES}

Briegleb, B. P., and D. H. Bromwich, 1998: Polar radiation budgets of the NCAR CCM3. J. Climate, 11, 1246-1268.

Clough, S. A., M. J. Iacono, and J. L. Moncet, 1992: Line-by-line calculations of atmospheric fluxes and cooling rates: Application to water vapor. J. Geophys. Res., 97, 15 761-15 785.

Comiso, J. C., 2000: Variability and trends in Antarctic surface temperatures from in situ and satellite infrared measurements. J. Climate, 13, 1674-1696.

Dalrymple, P. C., 1966: A physical climatology of the Antarctic Plateau. Studies in Antarctic Meteorology, M. J. Rubin, Ed., Antarctic Research Series, Vol. 9, Amer. Geophys. Union, 195-231.

Dürr, B., and R. Philipona, 2004: Automatic cloud amount detection by surface longwave downward radiation measurements. J. Geophys. Res., 109, D05201, doi:10.1029/2003JD004182.

Dutton, E. G., R. S. Stone, and J. L. Deluisi, 1989: South Pole surface radiation balance measurements April 1986 to February 1988. NOAA Data Rep. ERL ARL-17, 49 pp.

Guo, Z., D. H. Bromwich, and J. J. Cassano, 2003: Evaluation of polar MM5 simulations of Antarctic atmosphere circulation. Mon. Wea. Rev., 131, 384-411.

Hahn, C. J., S. G. Warren, and J. London, 1995: The effect of moonlight on observation of cloud cover at night, and application to cloud climatology. J. Climate, 8, 1429-1446.

Hines, K. M., R. W. Grumbine, D. H. Bromwich, and R. I. Cullather, 1999: Surface energy balance of the NCEP MRF and NCEP-NCAR reanalysis in Antarctic latitudes during FROST. Wea. Forecasting, 14, 851-866.

- D. D. Bromwich, P. J. Rasch, and M. J. Iacono, 2004: Antarctic clouds and radiation within the NCAR climate models. J. Climate, 17, 1198-1212.

Hudson, S. R., and R. E. Brandt, 2005: A look at the temperature inversion over the Antarctic Plateau. J. Climate, 18, 16731696.

Key, J. R., 2002: The cloud and surface parameter retrieval (CASPR) system for polar AVHRR user's guide, Part II. Cooperative Institute for Meteorological Satellite Studies, University of Wisconsin-Madison Tech. Rep., 36 pp.

Kuhn, M., A. J. Riordan, and I. A. Wagner, 1975: The climate of Plateau Station. Climate of the Arctic, G. Weller and S. A. Bowling, Eds., Amer. Meteor. Soc., 255-267.

Liu, H., K. Jezek, B. Li, and Z. Zhao, 2001: Radarsat Antarctic Mapping Project digital elevation model version 2. National Snow and Ice Data Center Tech. Rep., Digital media. [Available online at http://www.nsidc.org/data/nsidc-0082.html.]

Lubin, D., B. Chen, D. H. Bromwich, R. C. J. Somerville, W. Lee, and K. M. Hines, 1998: The impact of Antarctic cloud radiative properties on a GCM climate simulation. J. Climate, 11, $447-462$.

Mahesh, A., V. P. Walden, and S. G. Warren, 2001: Ground-based infrared remote sensing of cloud properties over the Antarc- tic Plateau. Part I: Cloud-base heights. J. Appl. Meteor., 40, $1265-1278$.

_, J. R. Campbell, and J. D. Spinhirne, 2005: Multi-year measurements of cloud base heights at South Pole by lidar. Geophys. Res. Lett., 32, L09812, doi:10.1029/2004GL021983.

Marty, C., and R. Philipona, 2000: The clear-sky index to separate clear-sky from cloudy sky situations in climate research $\mathrm{Geo}$ phys. Res. Lett., 27, 2649-2652.

- , and Coauthors, 2003: Downward longwave irradiance uncertainty under arctic atmospheres: Measurements and modeling. J. Geophys. Res., 108, 4358, doi:10.1029/2002JD002937.

Maslanik, J. A., J. Key, C. W. Fowler, T. Nguyen, and X. Wang, 2001: Spatial and temporal variability of satellite-derived cloud and surface characteristics during FIRE-ACE. J. Geophys. Res., 106 (D14), 15 233-15 249.

Meier, W. N., J. A. Maslanik, J. R. Key, and C. W. Fowler, 1997: Multiparameter AVHRR-derived products for Arctic climate studies. Earth Interactions, 1. [Available online at http:// EarthInteractions.org.]

Neff, W. D., 1999: Decadal time scale trends and variability in the tropospheric circulation over the South Pole. J. Geophys. Res., 104, 27 217-27 251.

Ohmura, A., and Coauthors, 1998: Baseline Surface Radiation Network (BSRN/WCRP): New precision radiometry for climate research. Bull. Amer. Meteor. Soc., 79, 2115-2136.

Pavolonis, M. J., and J. R. Key, 2003: Antarctic cloud radiative forcing at the surface estimated from the AVHRR Polar Pathfinder and ISCCP D1 datasets, 1985-1993. J. Appl. Meteor., 42, 827-840.

,-- , and J. J. Cassano, 2004: A study of the Antarctic surface energy budget using a polar regional model forced with satellite-derived cloud properties. Mon. Wea. Rev., 132, 654661.

Philipona, R., and Coauthors, 2001: Atmospheric longwave irradiance uncertainty: Pyrgeometers compared to an absolute sky-scanning radiometer, atmospheric emitted radiance interferometer, and radiative transfer model calculations. $J$. Geophys. Res., 106 (D22), 28 129-28 141.

Ramanathan, V., R. D. Cess, E. F. Harrison, P. Minnis, B. R. Barkstrom, E. Ahmad, and D. Hartmann, 1989: Cloudradiative forcing and climate: Results from the Earth Radiation Budget Experiment. Science, 243, 57-63.

Rossow, W. B., and L. C. Garder, 1993a: Cloud detection using satellite measurements of infrared and visible radiances for ISCCP. J. Climate, 6, 2341-2369.

, and - 1993b: Validation of ISCCP cloud detections. $J$. Climate, 6, 2370-2393.

_ and R. A. Schiffer, 1999: Advances in understanding clouds from ISCCP. Bull. Amer. Meteor. Soc., 80, 2261-2287.

Schiffer, R. A., and W. B. Rossow, 1983: The International Satellite Cloud Climatology Program (ISCCP): The first project of the World Climate Research Program. Bull. Amer. Meteor. Soc., 64, 779-784.

Schwerdtfeger, W., 1984: Weather and Climate of the Antarctic. Elsevier, $261 \mathrm{pp}$.

Sutter, M., B. Dürr, and R. Philipona, 2004: Comparison of two radiation algorithms for surface-based cloud-free sky detection. J. Geophys. Res., 109, D17202, doi:10.1029/ 2004JD004582.

Thomas, S. M., A. K. Heidinger, and M. J. Pavolonis, 2004: Comparison of NOAA's operational AVHRR-derived cloud amount to other satellite-derived cloud climatologies. J. Climate, 17, 4805-4822. 
Town, M. S., V. P. Walden, and S. G. Warren, 2005: Spectral and broadband longwave downwelling radiative fluxes, cloud radiative forcing and fractional cloud cover over the South Pole. J. Climate, 18, 4235-4252.

Walden, V. P., and Coauthors, 2001: The South Pole Atmospheric Radiation and Cloud Lidar Experiment (SPARCLE). Preprints, Sixth Conf. on Polar Meteorology and Oceanography, San Diego, CA, Amer. Meteor. Soc., 297-299.

Wang, X., and J. R. Key, 2003: Recent trends in Arctic surface, cloud, and radiation properties from space. Science, 299, $1725-1728$.

, and —, 2005a: Arctic surface, cloud, and radiation properties based on the AVHRR Polar Pathfinder dataset. Part I:
Spatial and temporal characteristics. J. Climate, 18, 25582574.

— , and 2005b: Arctic surface, cloud, and radiation properties based on the AVHRR Polar Pathfinder dataset. Part II: Recent trends. J. Climate, 18, 2575-2593.

Warren, S. G., C. J. Hahn, J. London, R. M. Chervin, and R. L. Jenne, 1986: Global distribution of total cloud cover and cloud type amounts over land. NCAR Tech Note TN$273+$ STR, 29 pp. + 200 maps.

WMO, 1996: Guide to meteorological instruments and methods of observation. World Meteorological Organization Tech. Rep., $242 \mathrm{pp}$. 